\title{
Melhor oportunidade cirúrgica para remoção de dente supranumerá- rio mesiodens em paciente infantil
}

Denise Campos Amaral' ${ }^{1}$, Carolina Cintra Gomes², Juliane Guimarães de Carvalho³.

${ }^{1}$ Especialista em Odontopediatria; Professora Adjunta da área de Ciclos de Vida do Curso de Odontologia do Centro Universitário UniEVANGÉLICA. ${ }^{2}$ Doutora em Radiologia Odontológica; Professora Titular da área de Diagnóstico e Cirurgia Oral do Curso de Odontologia do Centro Universitário UniEVANGÉLICA. ${ }^{3}$ Doutora em Biologia Oral; Professora Titular da área de Dentística do Curso de Odontologia do Centro Universitário UniEVANGÉLICA.

\begin{abstract}
Resumo
Objetivo: Este trabalho visa relatar um caso de exodontia de mesiodens em criança, diagnosticado precocemente, após a espera de momento oportuno para intervir de forma conservadora. Relato de caso: Paciente com 5 anos de idade e queixa principal de desconforto na região de incisivos superiores decíduos. Os exames clínico e radiográfico revelaram abaulamento em mucosa vestibular com fístula no dente 61 e anomalia dental diagnosticada como mesiodens na região de pré-maxila. O tratamento proposto foi exodontia imediata do dente 61 e intervalo de espera até erupção do supranumerário. Após um período de nove meses, estando o supranumerário já presente na cavidade bucal, o mesmo foi removido e a proservação foi realizada por 2 anos até a erupção do dente 21. Considerações finais: O diagnóstico precoce e a intervenção em momento oportuno favorecem a realização de intervenções conservadoras e cooperação da criança no procedimento realizado.
\end{abstract}

Palavras-chave: Dente supranumerário; Diagnóstico; Criança.

\section{Introdução}

Os dentes supranumerários são os que excedem a dentição normal, sendo esta anomalia conhecida também como hiperdontia. O tipo mais comum de dente supranumerário é o mesiodens que está situado entre os incisivos centrais superiores, de tamanho pequeno e forma conóide ${ }^{1,2}$.

A hiperdontia pode se desenvolver a partir da retenção dos dentes decíduos ou do desenvolvimento de dentes supranumerários decíduos e permanentes resultantes de um distúrbio no processo de organogênese. A etiologia destes dentes é incerta, mas várias causas foram sugeridas para sua presença, como atavismo, dicotomia do germe dentário, crescimento excessivo da lâmina dentária, fatores de hereditariedade e doenças gerais ${ }^{3}$.

A presença de mesiodens pode interferir na erupção normal de dentes permanentes assim como causar reabsorção radicular, problemas associados à oclusão, diastema e formação cística. Ainda há controversa no momento em que se deve remover o mesiodens. Alguns estudos mostram que a intervenção deve ser adiada até o desenvolvimento completo das raízes dos dentes adjacentes, enquanto outros propõem que a remoção deve ser realizada o mais rápido possível após o diagnóstico, no entanto, essa abordagem envolve o risco de danificar o desenvolvimento de germes dentários que estão próximos ${ }^{2,4}$.

A idade de diagnóstico varia com a diversidade de casos devido às variações de número, posicionamento (alinhado, invertido, erupcionado ou impactado), forma e tamanho dos supranumerários, e em muitos casos os exames complementares são indispensáveis5. O diagnóstico pode ser tardio já que os mesiodens podem permanecer retidos na cavidade bucal, assintomáticos, sendo visualizados apenas em radiografias de rotina ${ }^{6,7}$.

Esse trabalho visa relatar um caso de exodontia de mesiodens, em criança, diagnosticado precocemente e com espera de sua erupção.

\section{Relato de caso}

Paciente do gênero masculino, 5 anos de idade, leucoderma, compareceu a clínica escola, do Curso de Odontologia do Centro Universitário de AnápolisUniEVANGÉLICA, com queixa de desconforto na região de incisivos superiores decíduos. A avaliação clínica e radiográfica revelou abaulamento em mucosa vestibular com fístula no dente 61 e anomalia dental de número diagnosticada como mesiodens na região de pré-maxila (Figuras 1). O tratamento proposto foi exodontia imediata do dente 61 e intervalo de espera até

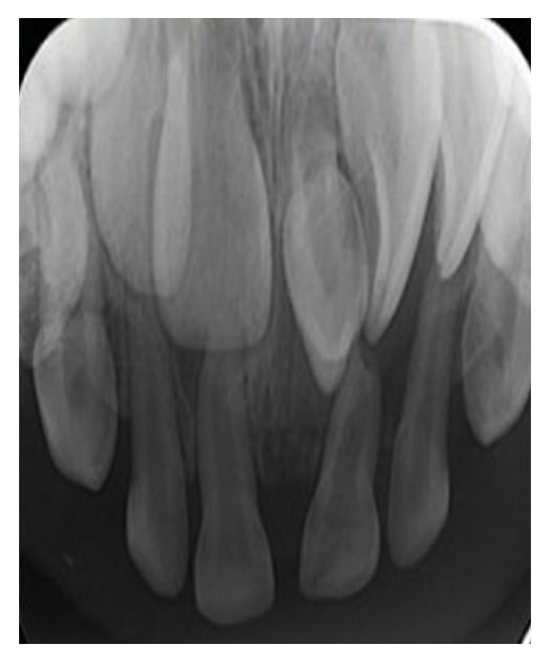

Figura 1 - Exame radiográfico inicial com diagnóstico de mesiodens. 


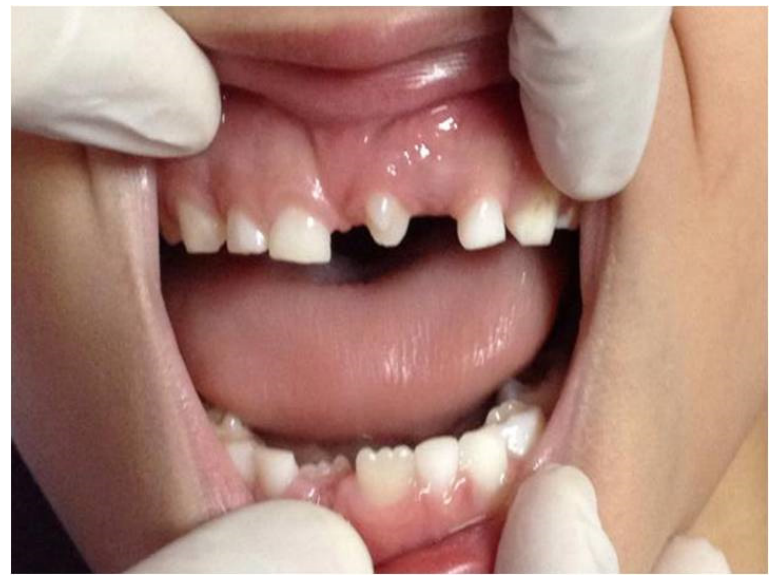

Figura 2 - Avaliação clínica e radiográfica após 9 meses para planejamento cirúrgico

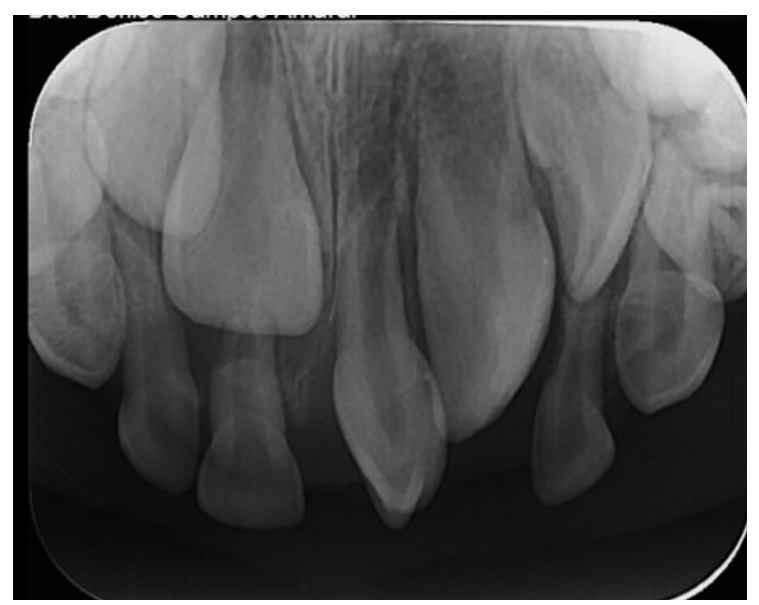

Figura 3 - Avaliação clínica e radiográfica após 9 meses para planejamento cirúrgico

erupção do supranumerário. Esta ação visou resguardar o paciente de um passo cirúrgico mais invasivo. Após um período de nove meses, estando o supranumerário já presente na cavidade bucal (Figuras 2 e 3), o mesmo foi removido sob anestesia local com técnica infiltrativa em fundo de vestíbulo e complementação palatina. $O$ anestésico utilizado foi lidocaína $2 \%$ com epinefrina, na concentração de 1:100.000. Com tecidos moles sindesmotomizados, o dente foi extraído com fórceps. Curetagem, irrigação com soro fisiológico foram seguidas por sutura simples com remoção dos pontos sete dias após a intervenção.

Após acompanhamento de dois anos evidenciou erupção completa do dente 21 (Figuras 4 e 5).

\section{Discussão}

A presença de dentes supranumerários na região anterior de maxila apresenta várias complicações funcionais e estéticas associadas. Dentre elas destacam-se clinicamente o atraso na erupção do dente perma-

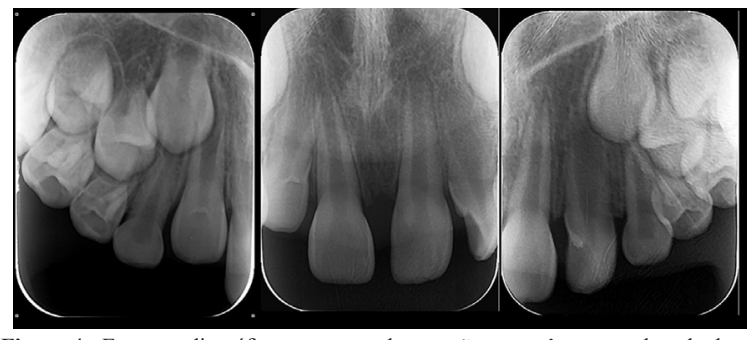

Figura 4 - Exame radiográfico apresentando erupção espontânea completa do dente 21.

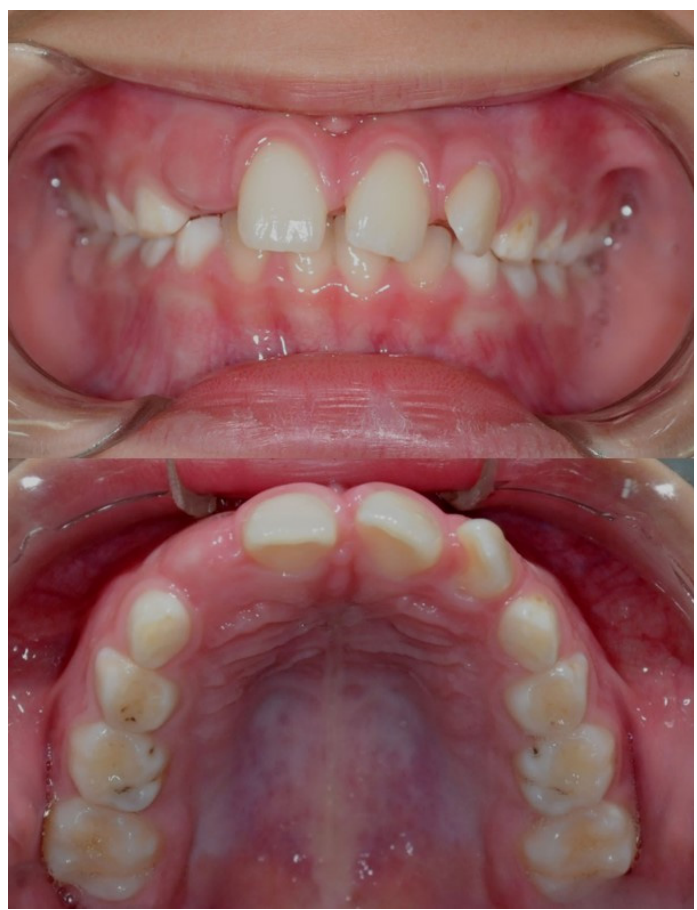

Figura 5 - Exame clínico presentando erupção espontânea completa do dente 21.

nente; o surgimento de diastemas e rotações dentárias; alteração do crescimento ósseo, do direcionamento e erupção do dente antagonista; a dificuldade de higienização e predisposição a gengivite e cárie; alteração no padrão de mastigação e oclusão. Radiograficamente outras complicações como impacção; desvio da rota de erupção normal; reabsorção radicular, perda do dente adjacente e lesões císticas ou tumorais ${ }^{3,8}$.

Considerando todas as complicações advindas de um dente supranumerário, o diagnóstico dever ser realizado precocemente, permitindo ao profissional realizar um tratamento mais conservador, visto que estas intercorrências e complicações ainda não estão estabelecidas 5 . No presente caso o diagnóstico foi dado precocemente já que o paciente compareceu a clínica com desconforto e presença de fístula na região do 61.

A anamnese e o exame clínico são fundamentais no sucesso do tratamento, podendo apontar para o diagnóstico quando se investiga sobre a sequência e cronologia de erupção, o número e o posicionamento dos dentes, a alteração de cor, forma, tamanho e mobilidade dos dentes presentes no arco dentário; a 
oclusão; alterações na palpação das estruturas ósseas de suporte dentário, visando excluir quaisquer anormalidades 5 .

Em muitos casos, para o diagnóstico de dentes supranumerários, exames complementares, como radiografias e tomografias, são indispensáveis e essenciais ao diagnóstico ${ }^{9}$. Nesse caso, a presença de dente supranumerário foi diagnosticada pela radiografia periapical. Dentre as opções de tratamento para dentes supranumerários, não há um protocolo padrão para todos os $\operatorname{casos}^{10}$. Alguns fatores devem ser considerados a fim de se estabelecer um plano de tratamento, como: grau de erupção dos dentes, localização e posicionamento do dente no arco, impacção de dentes adjacentes, gerando processos patológicos ou alterações nas estruturas anatômicas adjacentes; comprometimento estético, funcional, psicossocial e necessidade de tratamento ortodôntico ${ }^{4,9,11,12}$. O diagnóstico precoce também deve ser considerado quanto à avaliação do estágio de formação do dente, principalmente quanto à rizogênese do dente supranumerário e dos dentes adjacentes ${ }^{5}$.

Assim, após avaliação desses fatores, no caso relatado optou-se por extrair o dente 61, que estava comprometido por lesão de cárie, e esperar a erupção espontânea do dente supranumerário. Essa conduta foi realizada com intuito de preservar as estruturas anatômicas e gerar menos estresse na criança. A conclusão do caso demonstrou que além do diagnóstico, o plano de tratamento é imprescindível para o sucesso clínico.

\section{Considerações finais}

O diagnóstico precoce, além de reduzir possíveis danos à cavidade bucal como atraso no irrompimento do dente permanente, favorece a realização de intervenções conservadoras, consideradas ideais quando se refere a pacientes infantis.

\section{Referências}

1. Assed A, Borsatto MC.; Freitas AC. Anomalias dentárias. In: ASSED, S. Odontopediatria: bases científicas para a prática clínica. São Paulo: Artes Médicas, 2005. p.213-253.

2. Shih WY, Hsieh CY, Tsai TP. Clinical evaluation of the timing of mesiodens removal. J Chin Med Assoc. 2016 jun; 79: 345350.

3. Kumar DK, Gopal KS. An epidemiological study on suprenumerary teeth: a survey on 5000 people. J Clin Diagn Res. 2013 jul; 7(7): 1504-1507.

4. Meighani G, Pakdaman A. Diagnosis and Management of Supernumerary (Mesiodens): A Review of the Literature. J Dent (Tehran). 2010; 7(1):41-9.

5. Stringhini Junior E; Stang B; Oliveira LB. Dentes supranumerários impactados: relato de caso clínico Rev Assoc Paul Cir Dent. 2015; 69(1):89-94.

6. Nunes KM, et al. Dentes supranumerários: Revisão bibliográ- fica e relato de caso clínico. Rev Odontol Univ Cid São Paulo. 2015; 27(1):72-81.

7. Ata-Ali F, Ata-Ali J, Penarrocha-Oltra D, Penarrocha-Diago M. Prevalence, etiology, diagnosis, treatment and complications of supernumerary teeth. J Clin Exp Dent. 2014; 6(4): 4148.

8. Anegundi RT, Tegginmani VS, Battepati P, Tavargeri A, Patil $S$, Trasad $V$ et al. Jain $G$. Prevalence and characteristics of supernumerary teeth in a non-syndromic South Indian pediatric population. J Indian Soc Pedod Prev Dent. 2014 Jan-Mar; 32(1):9-12.

9. Neville BW, Damm DD, Allen CM, Bouquot JE. Patologia Oral e Maxilofacial. 3a. ed. Rio de Janeiro: 2009.

10. Ziegler CM, Klimowicz TR. A comparison between various radiological techniques in the localization and analysis of impacted and supernumerary teeth. Indian J Dent Res. 2013 May-Jun;24(3):336-41.

11. Lara TS, Lancia M, Silva Filho OM, Garib DG, Ozawa TO. Prevalece of mesiodens in orthodontic patients with deciduous and mixed dentition and its association with other dental anomalies. Dental Press J Orthod. 2013 nov-dec; 18(6): 93-9.

12. Mohan $\mathrm{S}$, Kankariya $\mathrm{H}$, Fauzdar $\mathrm{S}$. Impacted inverted teeth with their possible treatment protocols. J Maxillofac Oral Surg. 2012 Dec;11(4):455-7.

Recebido em : 21/07/2017

Aprovado em: 09/10/2017

Os autores declaram que não há conflitos de interesse.

\section{Autor correspondente:}

Denise Campos Amaral

Av. Universitária Km 3,5, Cidade Universitária - Anápolis/ GO CEP: 75083-515

Telefone:+55 (62) 999572851

e-mail: denisecamposamaral@gmail.com 